\title{
Limit on the scale of impact-related metal/silicate segregation on L chondrite parent(s)
}

\author{
JON M. FRIEDRICH* \\ Department of Earth and Planetary Sciences, American Museum of Natural History, \\ Central Park West at 79th Street, New York, NY 10024-5192, U.S.A.
}

(Received January 6, 2006; Accepted April 28, 2006)

\begin{abstract}
To assess the role of impact related reheating on compositional trends in the major elements of the L chondrite parent(s), I examined a suite of $37 \mathrm{~L}$ falls analyzed by Jarosewich (1990). After eliminating 8 samples prepared from quantities which differently sampled the chondrites considered, I found that suites of mildly-shocked (S3) and strongly-shocked (S4-S6) equilibrated L chondrite falls can be distinguished at statistically significant levels when compared based on their major element content. Graphical comparisons demonstrated that the differences arise because siderophiles are depleted with corresponding mass-balanced lithophile enrichment in strongly-shocked samples. Since the samples considered here were derived from volumes of between $1.5 \mathrm{~cm}^{3}$ and $4.7 \mathrm{~cm}^{3}$, we can conclude that statistically significant post-metamorphic metal(sulfide)/silicate segregation occurred on a scale of at least this size.
\end{abstract}

Keywords: shock reheating, impacts, L-chondrites, statistical analysis, differentiation

\section{INTRODUCTION}

The mineralogical, physical, and chemical properties of chondrites record early genetic processes within the solar system such as nebular condensation, accretion, and subsequent parent body metamorphism. For some meteoritic material, extensive chemical evolution ended with these episodes: post-metamorphic shock (re)heating had little or no significant impact on their present chemical composition. In the case of the $\mathrm{L}$ chondrite parent body or bodies, a late ( $500 \mathrm{Ma})$ episode of extreme shock events (Anders, 1964; Heymann, 1967; Bogard et al., 1995; Nakamura et al., 1990; Schmitz et al., 2003) left many portions at high (up to $1500^{\circ} \mathrm{C}$ ) residual temperatures and with shock-related petrographic alteration (Stöffler and Langenhorst, 1994; Stöffler et al., 1988, 1991). The more recent finding of high temperature and pressure mineral phases in especially L chondrites have both verified the extreme conditions experienced during planetesimal impacts and illustrated the tremendous complexity of shock processes (e.g., Chen et al., 1996; Tomioka and Fujino, 1997; Kimura et al., 2003 and references in them.)

Some compositional differences between L chondrites that experienced high degrees of shock loading and those that experienced only mild shock have been described.

*E-mail address: fried@amnh.org

Copyright $@ 2006$ by The Geochemical Society of Japan.
These differences include a loss of radiogenic noble gasses (e.g., ${ }^{40} \mathrm{Ar}$ and ${ }^{4} \mathrm{He}$ ) and thermally labile elements (e.g., $\mathrm{Rb}, \mathrm{Cs}, \mathrm{Se}, \mathrm{Ag}, \mathrm{Te}, \mathrm{Zn}, \mathrm{In}, \mathrm{Bi}, \mathrm{Tl}, \mathrm{Cd}$ ) in strongly-shocked samples (Dodd and Jarosewich, 1979; Huston and Lipschutz, 1984; Walsh and Lipschutz, 1982). Recently, Friedrich et al. (2004) investigated shock-induced differences in refractory trace elements in L chondrite falls using multivariate statistical analysis. We found moderate to very strong evidence for differences in refractory lithophiles [Rare Earth Elements (REE), Hf, Zr, Y, Sc, $\mathrm{Th}, \mathrm{U}, \mathrm{V}, \mathrm{Sr}$, and Ba], refractory siderophiles (Re, Ir, Mo, $\mathrm{Ru}, \mathrm{Pt}, \mathrm{Co}, \mathrm{Pd}, \mathrm{Au}$ ) as well as refining the previous moderately and highly volatile trace element difference observations (Lipschutz and Samuels, 1991; Walsh and Lipschutz, 1982; Friedrich et al., 2001, 2002).

Trace elements may be expected to display statistically significant variations as a result of thermal effects because their small absolute differences can be amplified into large relative differences during even mild thermal episodes. Although the high relative concentration of major elements ( $\mathrm{C}, \mathrm{Na}, \mathrm{Mg}, \mathrm{Al}, \mathrm{Si}, \mathrm{P}, \mathrm{S}, \mathrm{K}, \mathrm{Ca}, \mathrm{Cr}, \mathrm{Fe}$, $\mathrm{Ni}$ ) may preclude such differences from appearing within bulk shock-heated samples, the possibility exists. Ordinary chondrite impact melts can show up to percent-level major element differences (Dodd and Jarosewich, 1982a, b; Kong and Xie, 2003; Mittlefehldt and Lindstrom, 2001) when compared to their host chondrite's composition. These differences seem likely due to migration and subsequent macro-segregation of metal and silicate phases (Hörz et al., 2005; Rushmer et al., 2005) 
during week to month periods (Smith and Goldstein, 1977) of high residual temperature. In samples that did not experience complete shock-melting and melt/host segregation, was the shock-related thermal alteration enough to create observable and statistically significant differences in bulk major element content? Here, I examine bulk L chondrite major element data with univariate and multivariate statistics to consider the possibility of compositional differences between suites of strongly(S4-S6) and mildly- (S3) shocked L chondrite falls.

Additionally, to ensure my considered data set is compositionally representative and unbiased, I examine major element variations and their analytically-based origins and the impact of analytical actions and results on the above study. With trace elements, which are likely distributed within many phases of silicate and metal portions of a meteorite, perfect sampling of an analyzed sample would likely not significantly bias the results of a through statistical study. However, the sampling of major elements-especially since, as the name suggests, these elements comprise the near total of the metal and silicate portions of a sample-may introduce bias to a thorough study of shock-related heating. Finally, I will examine if the deconvolution of sample mass effects and analytical bias can place limitations on the physical scale of partial melting during post-metamorphic shock-related (re)heating: i.e., Can we use major element data of differently and "representatively" sampled L chondrites to place a physical limit on the scale of metal/silicate separation as a function of shock loading?

\section{Methods AND SAMPLE Considerations}

To consider differences between individual elemental content in suites of mildly- and strongly-shocked L chondrite falls, I employ several separate statistical tests. In each case the null hypothesis is that my two suites of $\mathrm{L}$ chondrites have identical chemical compositions. To compare the content of individual elements, I first use the familiar Student's t-test. This statistic assumes that the considered populations have a symmetric normal distribution and the variances of the two sets are equal. Although these assumptions may be valid, I also compare my suites' elemental content with a nonparametric test, the Wilcoxon statistic. This test is especially appropriate when two populations are simply shifted with respect to each other (but retains the original distribution function) and does not have the underlying assumptions that the $\mathrm{t}$ test uses (such as knowing the elemental data's distribution function has a normal probability density).

For additional comparisons, I use the multivariate techniques of linear discriminant analysis (LDA) and logistic regression (LR) (Lipschutz and Samuels, 1991; Wolf and Lipschutz, 1995a; Friedrich et al., 2004). These methods are useful for compositional comparisons because they can consider many elements concurrently and can identify subtle relationships among these elements. As mentioned above, I define two sample subsets defined by their degree of shock loading and compare their compositions to assess the extent to which their compositions reflect their petrographic shock classification. A review of the principles behind LDA and LR was given in Friedrich et al. (2004), but for completeness I should mention that LDA uses a standard linear regression model to obtain a normal multivariate distribution function and assumes that the probability of membership in either the mildly-shocked (S3) or strongly-shocked (S4-S6) is equal. LR is conceptually similar to LDA, but it is less sensitive to the actual real-life distribution of the multivariate data (Wolf and Lipschutz, 1995b and references therein). For example, actual $\mathrm{MgO}$ data may not be best described as normally distributed, but rather as e.g., log-normal or beta distributed. The LR method also assumes equal probability of being in the mildly- or strongly-shocked groups.

Both the LDA and LR techniques in their standard form are, as described to above, model-dependent, assuming a specific distribution function to describe independent variables (elements in our case). However, if shapes of the distribution functions are not normal, statistical results may be biased. To reduce the likelihood of this model-dependent bias, I use a proven bootstrap method developed by Lipschutz and Samuels (1991) called randomization-simulation to simulate random noise in my data set's elemental distributions. This technique generates a new data set by randomly assigning meteorites to one of two sample suites nominally classified as mildlyand or strongly-shocked. These randomly generated suites must be of the same size as those displayed by the original data. So, my random suites are assigned such that I have 11 "mildly-" and 18 "strongly-shocked" samples (see next sections). Next, each randomly-generated pair of suites is compared using either LDA or LR on the basis of their compositional data. After generating at least 1000 of these simulated data sets $(<1000$ in some cases-see below), I calculate a model-independent p-value by simply counting the number of randomly-generated sets which have as few as or fewer misclassifications than in the actual case (Lipschutz and Samuels, 1991). The smaller the p-value, the more significant the comparison.

Later in this section, I employ cluster analysis, a multivariate technique useful for detecting groupings within datasets. For all statistical analyses, I use JMP (Version 3.1.6.2, SAS Institute Inc.) software and replicate randomization simulations were performed using Automate (Version 4.0, Network Automation, Inc).

In Table 1, I show the $37 \mathrm{~L}$ chondrite falls initially considered in this study. All chemical data are taken from 
Table 1. L chondrite falls, type, shock classification. For reasons of unrepresentative sampling, samples without abbreviations are not included in statistical comparisons (see Methods and Sample Considerations and Fig. 2)

\begin{tabular}{|c|c|c|c|}
\hline Meteorite & Abbr. & Petr. type & Shock* \\
\hline Bald Mountain & BLM & 4 & S4 \\
\hline Ausson & AUS & 5 & S3 \\
\hline Crumlin & CRU & 5 & S4 \\
\hline Elenovka & ELV & 5 & S3 \\
\hline Guibga & GUI & 5 & S3 \\
\hline Homestead & HOM & 5 & S4 \\
\hline Honolulu & HLU & 5 & S3 \\
\hline Jhung & JHU & 5 & S3 \\
\hline Malakal & MAL & 5 & S4 \\
\hline Shelburne & SHL & 5 & S4 \\
\hline Apt & APT & 6 & S4 \\
\hline Aumale & AUM & 6 & S4 \\
\hline Bruderheim & BRU & 6 & S4 \\
\hline Chantonnay & & 6 & S4 \\
\hline Denver & DEN & 6 & S4 \\
\hline Girgenti & & 6 & S4 \\
\hline Karkh & KAK & 6 & S4-S5 \\
\hline Kunashak & & 6 & $\mathrm{~S} 4$ \\
\hline Kuttippuram & KUT & 6 & S3 \\
\hline Kyushu & & 6 & S5 \\
\hline La Criolla & LAC & 6 & S4 \\
\hline L'Aigle & LAL & 6 & S3 \\
\hline Leedey & LED & 6 & S4 \\
\hline Louisville (light) & LOU & 6 & S4 \\
\hline Modoc (1905) & MOD & 6 & S4 \\
\hline Nejo & NEJ & 6 & S3 \\
\hline New Concord & & 6 & S4 \\
\hline Paranaiba & PAR & 6 & S6 \\
\hline Ramsdorf & & 6 & S4 \\
\hline Segowlie & & 6 & S3 \\
\hline Tathlith & TAT & 6 & S3 \\
\hline Tourinnes-la-Grosse & TLG & 6 & S3 \\
\hline Tuan Tuc & TTU & 6 & S4-S5 \\
\hline Valdinizza & & 6 & S4 \\
\hline Vouillé & VOU & 6 & S4 \\
\hline Wethersfield (1971) & W71 & 6 & S4 \\
\hline Wethersfield (1982) & W82 & 6 & S3 \\
\hline
\end{tabular}

*From Friedrich et al. (2004).

Jarosewich (1990) and were previously deemed "chemically representative" samples based on their trace element content(s), especially the REE, which can be used as a rough indicator for chondrite sample heterogeneity (Friedrich et al., 2003 and references therein). To investigate if I could expand my meteorite-element-shock database to include samples analyzed for major elements by other analysts, I preformed cluster analysis, a multivariate statistical tool for detecting groupings within data sets such as these (Everett, 1993), on three sample aliquots each analyzed by three different laboratories (Fig. 1). Comparisons are based on oxides of $\mathrm{Na}, \mathrm{Mg}, \mathrm{Al}$,
$\mathrm{Si}, \mathrm{P}, \mathrm{K}, \mathrm{Ca}, \mathrm{Ti}, \mathrm{Cr}, \mathrm{Mn}$, and elemental $\mathrm{Fe}_{\text {total }}(\mathrm{n}=11)$ compiled from Metbase 7.1 (Koblitz, 2005). Ideally, clusters within Fig. 1 should show the same meteorite analyses grouping earliest (on the left) irrespective of analysis origin: such a result would suggest no inter-laboratory analytical bias. Actual results (Fig. 1a) show a striking bias with respect to the analyzing laboratory: samples analyzed by laboratory 2 cluster tightly while laboratories 1 and 3 show less bias among each other. Removing laboratory number 2 (Fig. 1b) from the comparison, and re-performing the cluster analysis again shows groupings as a result of analysis laboratory origin, not sample. Nittler et al. (2004), in an examination of chondrite major element data, also noted bias between analysts.

Although Wolf and Lipschutz (1995a, b) found intralaboratory analyst bias negligible with respect to multivariate statistical inferences based on thermally volatile trace elements, the possibility of inter-laboratory bias with respect to major element content cannot be discounted based on the results of cluster analysis. Based on these results, I chose not to expand my elemental analysis database beyond the Jarosewich (1990) data. Mildlyshocked L chondrite specimens are rare and the unfortunate consequence of using only the Jarosewich (1990) data set is that S1 and S2 shock stage samples are not represented in my mildly-shocked sample suite in this study. In a previous trace element study of chemical effects of shock loading (Friedrich et al., 2004), we were able to supplement the Jarosewich-prepared mildly-shocked samples with additional mildly-shocked samples without introducing noticeable statistical bias. Because major element data is unavailable for these supplementary samples or major element data was obtained by analysts other than Jarosewich, I am forced to limit the mildly-shocked suite to S3 samples in this work.

Major elements are more prone to sampling effects than their trace element kin, especially since these elements comprise nearly $100 \%$ of the total portions of a sample. To consider other possible sources of bias, such as sampling, which may be present within our currently selected suite of data, I examined the most likely source of bias: that of the "nugget effect". In our case, this is the reduced metal component contained within our suite of $\mathrm{L}$ chondrite samples. For the analytical preparation of the samples considered here, between $0.9 \mathrm{~g}$ and $26.8 \mathrm{~g}$ [0.25 $\mathrm{cm}^{3}$ and $8 \mathrm{~cm}^{3}$, based on the mean L chondrite volume density of $3.31 \mathrm{~cm}^{3} / \mathrm{g}$ given by Wilkison et al. (2003)] of a meteorite was taken, pulverized, and the resulting powders were separated into $<100$ mesh (silicate) and $>100$ mesh (metal) fractions (E. Jarosewich, personal communication). While this method is likely among the best available for accurately sampling heterogeneous samples such as chondrites for chemical analysis (Wilson, 1964), it could introduce some extraneous errors when consid- 
a

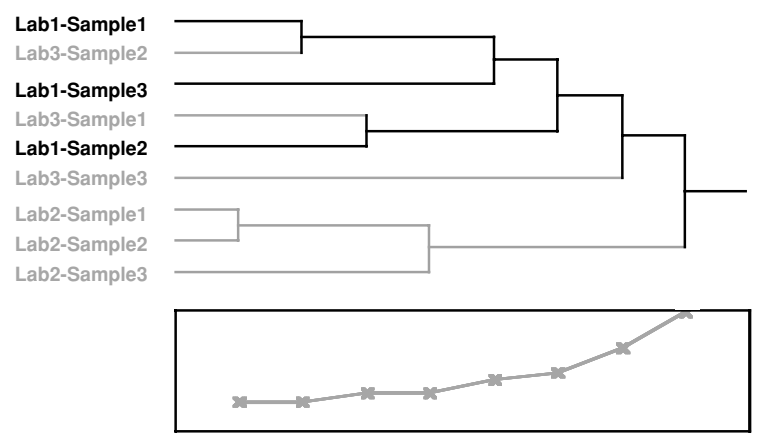

Fig. 1. Dendrograms of multivariate cluster analysis of major element data (oxides of $\mathrm{Na}, \mathrm{Mg}, \mathrm{Al}, \mathrm{Si}, \mathrm{P}, \mathrm{K}, \mathrm{Ca}, \mathrm{Ti}, \mathrm{Cr}, \mathrm{Mn}$, and elemental $F e_{\text {total }}$ produced by (a) 3 different laboratories on 3 identical L chondrite samples. Removing Lab2 from consideration yields the results shown in: (b) 2 different laboratories on the same 3 identical samples. Ideally, clusters within Fig. 1 should show the same meteorite analyses grouping earliest (on the left) irrespective of analysis origin: such a result would suggest no inter-laboratory analytical bias. Due to resolvable laboratory bias and the possible effect on the outcome of this study, I perform statistical analysis on data from only one laboratory (see Methods and Sample Considerations).

ering our sample suite with multivariate statistical methods because such methods are more sensitive to interelement relationships, unlike univariate methods.

For example, in Fig. 2 I show analyzed \% $\mathrm{Fe}_{\text {metal }}$ content versus the quantity of L chondrite used for the preparation of the samples considered here, which are also indicated for their degree of shock loading. Multivariate analyses are typically unaffected by additional layers of convolved distribution functions (e.g., sampling effects) resting upon the indigenous elemental variations (possibly due to shock loading) as long as those additional sources of variation are applied uniformly to a sample suite. In our case, a majority of the samples come from a sampled mass of 5-15 g (Fig. 2). Eight samples (Ramsdorf, Chantonnay, Girgenti, Valdinizza, Kunashak, New Concord, Kyushu, Segowlie) were prepared from significantly larger or smaller L chondrite samples or their total metal content indicates they were likely under-sampled with respect to metal (Fig. 2). For an exact multivariate analysis, I exclude these samples from statistical consideration leaving a suite of $29 \mathrm{~L}$ falls. Two samples, Ramsdorf and Chantonnay, are both intensively shocked and their respective extremely higher and lower apparent metal content (Fig. 2) could be the result of the segregation of metal and silicate (see Results and Discussion) which made their representative sampling more difficult (Dodd and Jarosewich, 1981). The resulting considered suite of samples suggests some bias with respect to shock loading: mildly-shocked initial starting material was slightly below that of the strongly-shocked material. This supposed bias is insignificant relative to the deviations caused by the extreme outliers as cluster analysis of the now reduced sample suite $(n=29)$ shows no clustering with respect to sample mass when compared using

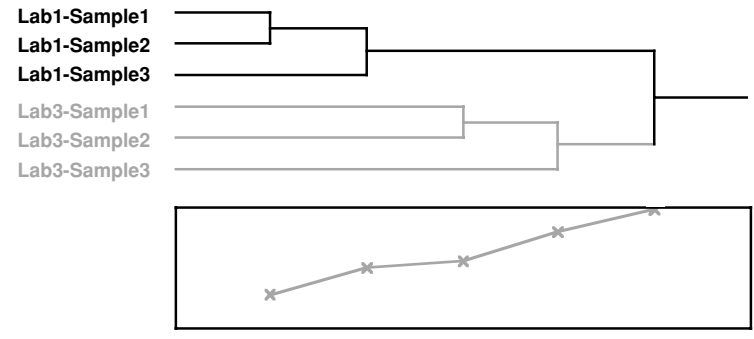

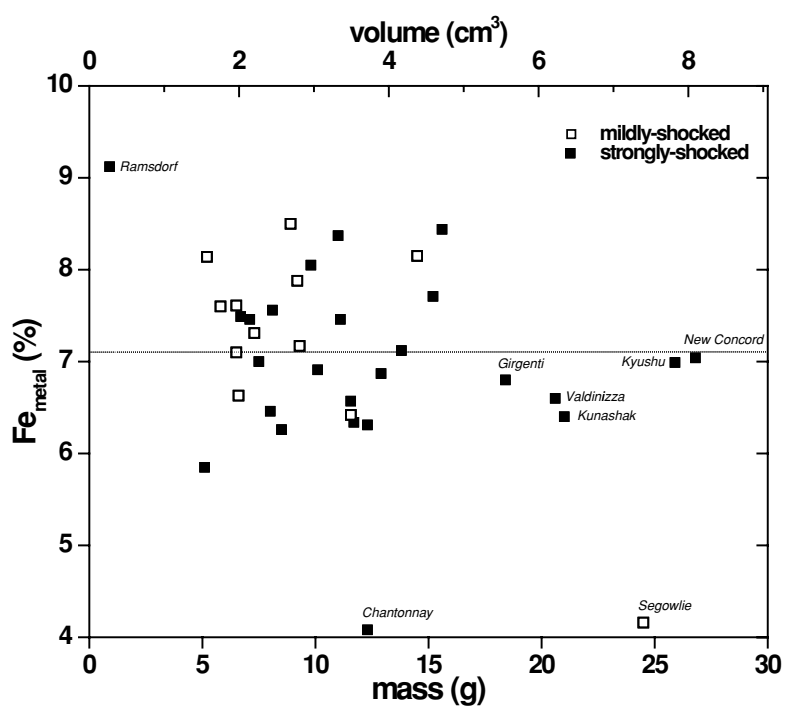

Fig. 2. Fe $e_{\text {metal }}$ content variation with total L chondrite sampled and degree of shock loading. Taken as a whole, the data suggests an asymptotic approach to an L chondrite mean of $7.08 \%$ metal, represented by dotted line, with larger samples. Mildly-shocked (S3) samples were generally derived from lower than average sample size of $11.5 \mathrm{~g}$. To avoid bias during statistical considerations, labeled samples were excluded from multivariate comparisons (see Methods and Sample Considerations). Since there is a strikingly significant multivariate statistical difference between mildly-and strongly-shocked in samples taken from $\sim 1 \mathrm{~cm}^{3}-5 \mathrm{~cm}^{3}$, the physical scale of shockinduced metal-silicate segregation due to impact (re)heating was at least this volume (Table 3, Fig. 4). 
Table 2. Elemental and elemental oxide means and associated $1 \sigma$ standard deviation of suites of mildly-shocked (S3) and strongly-shocked (S4-S6) L chondrites considered in this study (cf., Figs. 3 and 4)

\begin{tabular}{|c|c|c|c|c|c|}
\hline \multirow[t]{2}{*}{ Element } & \multirow[t]{2}{*}{ Conc. } & \multicolumn{2}{|c|}{ Entire suite $(\mathrm{n}=37)$} & \multicolumn{2}{|c|}{ Statistically compared suite $(n=29)$} \\
\hline & & $\begin{array}{l}\text { Mildly-shocked } \\
\quad(\mathrm{S} 3, \mathrm{n}=12)\end{array}$ & $\begin{array}{l}\text { Strongly-shocked } \\
(\mathrm{S} 4-\mathrm{S} 6, \mathrm{n}=25)\end{array}$ & $\begin{array}{l}\text { Mildly-shocked } \\
\quad(\mathrm{S} 3, \mathrm{n}=11)\end{array}$ & $\begin{array}{c}\text { Strongly-shocked } \\
(\mathrm{S} 4-\mathrm{S} 6, \mathrm{n}=18)\end{array}$ \\
\hline $\mathrm{C}$ & $\%$ & $0.07 \pm 0.05$ & $0.13 \pm 0.13$ & $0.07 \pm 0.05$ & $0.12 \pm 0.13$ \\
\hline $\mathrm{Na}_{2} \mathrm{O}$ & $\%$ & $0.958 \pm 0.068$ & $0.949 \pm 0.049$ & $0.958 \pm 0.071$ & $0.950 \pm 0.047$ \\
\hline $\mathrm{MgO}$ & $\%$ & $24.4 \pm 0.4$ & $24.9 \pm 0.4$ & $24.5 \pm 0.4$ & $24.9 \pm 0.3$ \\
\hline $\mathrm{Al}_{2} \mathrm{O}_{3}$ & $\%$ & $2.27 \pm 0.08$ & $2.28 \pm 0.10$ & $2.27 \pm 0.08$ & $2.26 \pm 0.10$ \\
\hline $\mathrm{SiO}_{2}$ & $\%$ & $39.4 \pm 0.5$ & $39.7 \pm 0.6$ & $39.5 \pm 0.5$ & $39.9 \pm 0.6$ \\
\hline $\mathrm{P}_{2} \mathrm{O}_{5}$ & $\%$ & $0.223 \pm 0.052$ & $0.216 \pm 0.033$ & $0.225 \pm 0.054$ & $0.217 \pm 0.032$ \\
\hline $\mathrm{K}_{2} \mathrm{O}$ & $\%$ & $0.113 \pm 0.017$ & $0.108 \pm 0.009$ & $0.112 \pm 0.017$ & $0.109 \pm 0.009$ \\
\hline $\mathrm{CaO}$ & $\%$ & $1.84 \pm 0.07$ & $1.82 \pm 0.08$ & $1.85 \pm 0.05$ & $1.83 \pm 0.08$ \\
\hline $\mathrm{Cr}_{2} \mathrm{O}_{3}$ & $\%$ & $0.530 \pm 0.045$ & $0.526 \pm 0.035$ & $0.532 \pm 0.047$ & $0.526 \pm 0.039$ \\
\hline $\mathrm{Fe}_{\text {total }}$ & $\%$ & $22.5 \pm 0.7$ & $21.9 \pm 0.8$ & $22.5 \pm 0.7$ & $21.8 \pm 0.74$ \\
\hline $\mathrm{Ni}$ & $\%$ & $1.27 \pm 0.09$ & $1.23 \pm 0.11$ & $1.27 \pm 0.10$ & $1.25 \pm 0.12$ \\
\hline $\mathrm{Fe}_{\text {metal }}$ & $\%$ & $7.22 \pm 1.15$ & $7.01 \pm 0.99$ & $7.50 \pm 0.65$ & $7.12 \pm 0.75$ \\
\hline $\mathrm{FeS}$ & $\%$ & $6.13 \pm 0.67$ & $5.60 \pm 0.94$ & $6.11 \pm 0.70$ & $5.69 \pm 1.00$ \\
\hline $\mathrm{FeO}$ & $\%$ & $14.3 \pm 0.5$ & $14.5 \pm 1.20$ & $14.3 \pm 0.6$ & $14.1 \pm 1.04$ \\
\hline
\end{tabular}

$\mathrm{SiO}_{2}, \mathrm{MgO}, \mathrm{Fe}_{\text {total }}$ and $\mathrm{Fe}_{\text {metal }}$ contents.

The resulting suite available for comparison consists of 1 L4, 9 L5, and 19 L6 chondrites. This distribution of petrographic type will not bias results or conclusions. Kallemeyn et al. (1989) remarked that there were no significant differences in elemental abundance with respect to petrographic type in ordinary chondrites of each chemical group while Friedrich et al. (2004) concluded shock loading (not petrographic type) was the dominant factor producing elemental signatures in L chondrites. In fact, the sample suite that I consider here is a sub-suite of that considered by Friedrich et al. (2004) who demonstrated no statistical significance variations of trace element content with petrographic type.

Rubin (2004) has observed petrographic evidence for the post-shock annealing in a number of chondrites. That is, these materials may have experienced heavy degrees of shock loading followed by unrelated episodes of heating significant enough to anneal the petrographic shock features in the previously strongly-shocked material. If any of the samples considered here had experienced such a history, what would the effect be on the statistical comparisons in this study and the conclusions drawn from them? If only portions of my considered sample suite had experienced post-shock annealing and the identical chemical effects we will investigate here were also present during previous shock episodes, this would only serve to make comparisons made on samples (which presumably only have been classified for shock in terms of the most recent shock episode) in my suite more difficult because of the increased convolution of the dataset.

For future statistical comparisons, my considered suite of $29 \mathrm{~L}$ chondrites (Table 1) contains 11 (38\%) mildlyshocked (S3) and 18 (62\%) strongly-shocked (S4-S6) L chondrite falls. The known distribution of both shockclassified L falls and all shock-classified L chondrites is $\sim 55 \%$ mildly-shocked and $\sim 45 \%$ strongly-shocked (Grady, 2000; Koblitz, 2005). For the statistical comparisons performed here, it is not important for the sample suite to be representative of the current population of $\mathrm{L}$ falls or total L chondrites: the only result of my selected suite is that the strongly-shocked (elemental) parameters are better constrained than those of the mildly-shocked suite especially since there are no S1 or S2 samples represented in my database.

\section{RESULTS AND DISCUSSION}

In Table 2, I show elemental and elemental oxide means and associated $1 \sigma$ standard deviation of suites of mildly-shocked (S3) and strongly-shocked (S4-S6) L chondrites considered in this study. For completeness, I show means and standard deviations for both the initially considered suite (see above Methods and Sample Considerations) of equilibrated $\mathrm{L}$ chondrites and the $\mathrm{n}=29$ statistically compared equilibrated $\mathrm{L}$ suite. To facilitate comparison, in Fig. 3 I show mean strongly-shocked elemental and elemental oxide data normalized to the mean of the mildly-shocked suite organized by increasing $\mathrm{z}$ of the primary element for my suite of $29 \mathrm{~L}$ falls (open symbols). At first glance, lithophiles are generally enriched in strongly-shocked samples while siderophiles are generally depleted. To ensure that these variations are not based on sample size variations, I also show data for all 


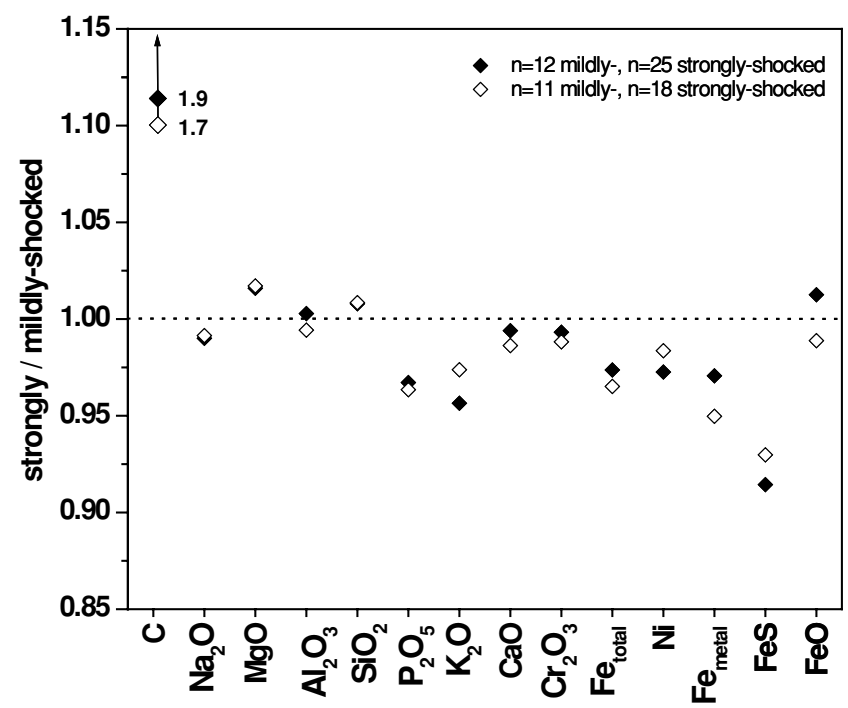

Fig. 3. Comparisons of major element contents of mildly (S3)and strongly (S4-S6)-shocked equilibrated L chondrites arranged by increasing $z$ in my full suite (closed symbols) and statistically-compared suite (open symbols). Both suites demonstrate trends described in the text regardless of which suite is considered. Univariate statistical treatments demonstrate moderate to strong evidence for a statistical difference in $\mathrm{MgO}$ and $\mathrm{Fe}_{\text {total }}$. Elements showing larger depletions (e.g., $\left.\mathrm{FeS}\right)$ are not significant when considered individually because of the greater variability (standard deviation) of individual meteorite-element data (cf., Fig. 4).

37 chondrites (closed symbols) deemed representative based on trace element but not on major element contents (cf., Fig. 2). The same trends are apparent in both suites considered (Fig. 3). In Friedrich et al. (2004), we briefly noted that there was a calculable overall massbalance between silicate and metal fractions within mildly and strongly-shocked chondrite suites taken as a whole: this relationship holds with suites of the samples compared here. Moderately volatile elements (e.g., Na, P, K) show depletions in strongly-shocked samples. Carbon is, on average, enriched by nearly $2 \times$ in the strongly-shocked samples, however $\mathrm{C}$ variation within and among mildlyand strongly-shocked suites is large and the significance of this observation is questionable, but a relation between shock and bulk carbon content is not impossible (Semenenko and Golovko, 1994).

To test the null hypothesis of identical compositions in mildly- and strongly-shocked samples, I will next use statistical tests to determine the probability of rejecting the null hypothesis of equal composition with high confidence. In each of both the univariate and multivariate statistical comparison metrics used, the lower the test value, the more significant the difference (the lower the chance of incorrectly rejecting the null hypothesis) between the considered suites. For ease of discussion, I will consider statistical results of $<0.05$ to show strong evidence (i.e., a confidence of $95 \%$ ) and results of $<0.1$ to be a moderately significant result. Of 14 elements considered (e.g., Fig. 3), only $\mathrm{MgO}$ and $\mathrm{Fe}_{\text {total }}$ show strong evidence using the univariate t-test with values of 0.006 and 0.010 respectively. The Wilcoxon univariate nonparametric test shows nearly the same results, which indicates that the underlying assumptions of the t-test may be valid. Other elemental differences, when individually compared, are not statistically significant as per my definitions. In the case of e.g., $\mathrm{K}_{2} \mathrm{O}$ or $\mathrm{FeS}$, which show depletions of $3-8 \%$, the data fails to demonstrate a statistical difference because of the data's high variability. Although it is apparent that the more volatile nature of these components causes a general depletion with additional post-metamorphic reheating (Fig. 3), that same property results in greater variability in samples as a whole.

For a more detailed comparison of the qualitative (Fig. 3) and above quantative properties of our sample suite, in Fig. 4, I show box and whisker plot comparisons of $\mathrm{SiO}_{2}, \mathrm{MgO}, \mathrm{Fe}_{\text {total }}$, and $\mathrm{FeS}$ bulk elemental analysis data between suites of mildly- and strongly-shocked L chondrite falls. Individual data are shown as points while the box shows the median as a line across the middle and the quartiles (25th and 75 th percentiles) as the ends. Outlying bars are $95 \%$ confidence intervals. We see in more detail the enrichment of lithophiles in strongly-shocked samples and the depletion of siderophiles and volatiles ( $\mathrm{S}$ as $\mathrm{FeS}$ in this case). The tight clustering of $\mathrm{MgO}$ data seems based on a fortuitous compositional clustering of strongly-shocked data, making the sample variance extremely low-however, the trend is verifiably present because the lithophile $\mathrm{SiO}_{2}$ exhibits the same trend.

In Table 3, I show results of multivariate statistical comparisons based on suites of major elements $\left(\mathrm{SiO}_{2}\right.$, $\mathrm{MgO}, \mathrm{Fe}_{\text {total }}, \mathrm{Fe}_{\text {metal }}, \mathrm{FeS}, \mathrm{Al}_{2} \mathrm{O}_{3}, \mathrm{CaO}, \mathrm{Ni}, \mathrm{Na}_{2} \mathrm{O}, \mathrm{Cr}_{2} \mathrm{O}_{3}$, $\mathrm{P}_{2} \mathrm{O}_{5}, \mathrm{~K}_{2} \mathrm{O}, \mathrm{C}$ ) between mildly- and strongly-shocked $\mathrm{L}$ falls using the metrics LDA and LR. Although $\mathrm{FeO}$ is compared in Fig. 3, I exclude it here because this constituent is difference-calculated from other Fe components (Jarosewich, personal communication) and inclusion would entail doubly-loading Fe elemental variables in the multivariate analyses.

In previous uses of multivariate statistics and randomization-simulation, there were issues of over determination of data sets (Lipschutz and Samuels, 1991; Friedrich et al., 2004), i.e., the number of meteorite-element data were nearly equal to greater than the number of samples and a clear separation of the suites was guaranteed: results appear significant regardless of statistical meaning. Since the maximum number of elements considered here is 13 (Table 3), and the statistically-com- 

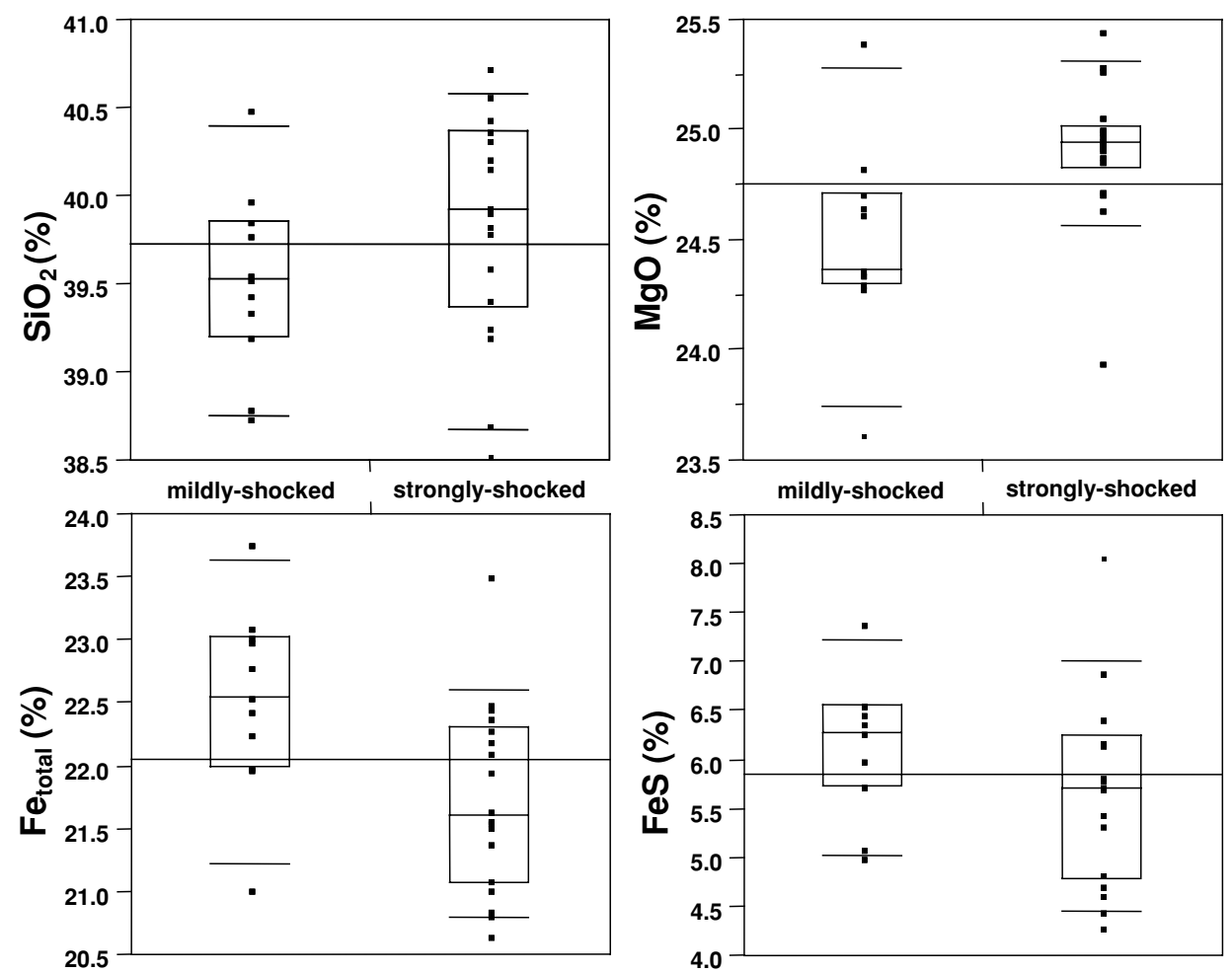

Fig. 4. Box and whisker plots of mildly-shocked $(n=11)$ and strongly-shocked $(n=18)$ L chondrite falls. Individual data are shown as points while the box shows the median as a line across the middle and the quartiles (25th and 75th percentiles) as the ends. Outlying bars are $95 \%$ confidence intervals. These major element relationships show that strongly-shocked samples are generally enriched in refractory lithophiles while conversely depleted in siderophile content and volatile content.

pared meteorite suite contains 29 L falls (Table 1), overdetermination may be a concern. To test if over determination is occurring during our statistical comparisons, we can compare the model dependent and model independent results. In our case there is no indication that even the comparisons based on all 13 elements are over-determined.

We can use the randomization simulation procedure to cross-validate the significance of our tested multivariate models to ensure that the values are robust. To avoid dependent variable (element) selection bias, I will compare three suites of elements: lithophiles and siderophiles, lithophiles only, and siderophiles only. I will then repeatedly remove elements based on their whole-rock concentration. We might expect that as elements are removed the probability of a significant result is decreased because the trace nature of the element, and hence amplification of any shock-related effect, would make a significant result more likely.

In all cases (lithophiles and siderophiles, lithophiles, siderophiles) except two, model dependent LR yields either moderately or highly significant results-rejecting the null hypothesis of identical chemical content with respect to shock loading can be done with confidence (Table 3). Model-dependent LDA becomes increasingly significant as elements are removed from the lithophile and siderophile suite. Lithophiles alone treated with LDA also become more significant as the more thermally labile elements are removed (Table 3). This is likely because of the more volatile nature of elements such as $\mathrm{Na}$, $\mathrm{P}$, and $\mathrm{K}$. Again, as mentioned above, they do show high variability and although they tend toward depletion in highly-shocked samples, their variability shields statistically significant results. Siderophiles, when examined alone, yield no to moderate significance with respect to shock loading examined with model dependent LDA. In the case of model dependent LDA, rejecting the null hypothesis can be done with moderate to strong significance in cases where the elements which are the compositional majority (e.g., $\mathrm{Mg}, \mathrm{Si}, \mathrm{Fe}$ ) are considered-somewhat anti-intuitively since we may expect the trace elements to play a greater distinguishing role.

I show an example of model independent result calculation in Fig. 5. This shows moderate to strong evidence for a significant major-element compositional difference between suites of mildly- and strongly-shocked 


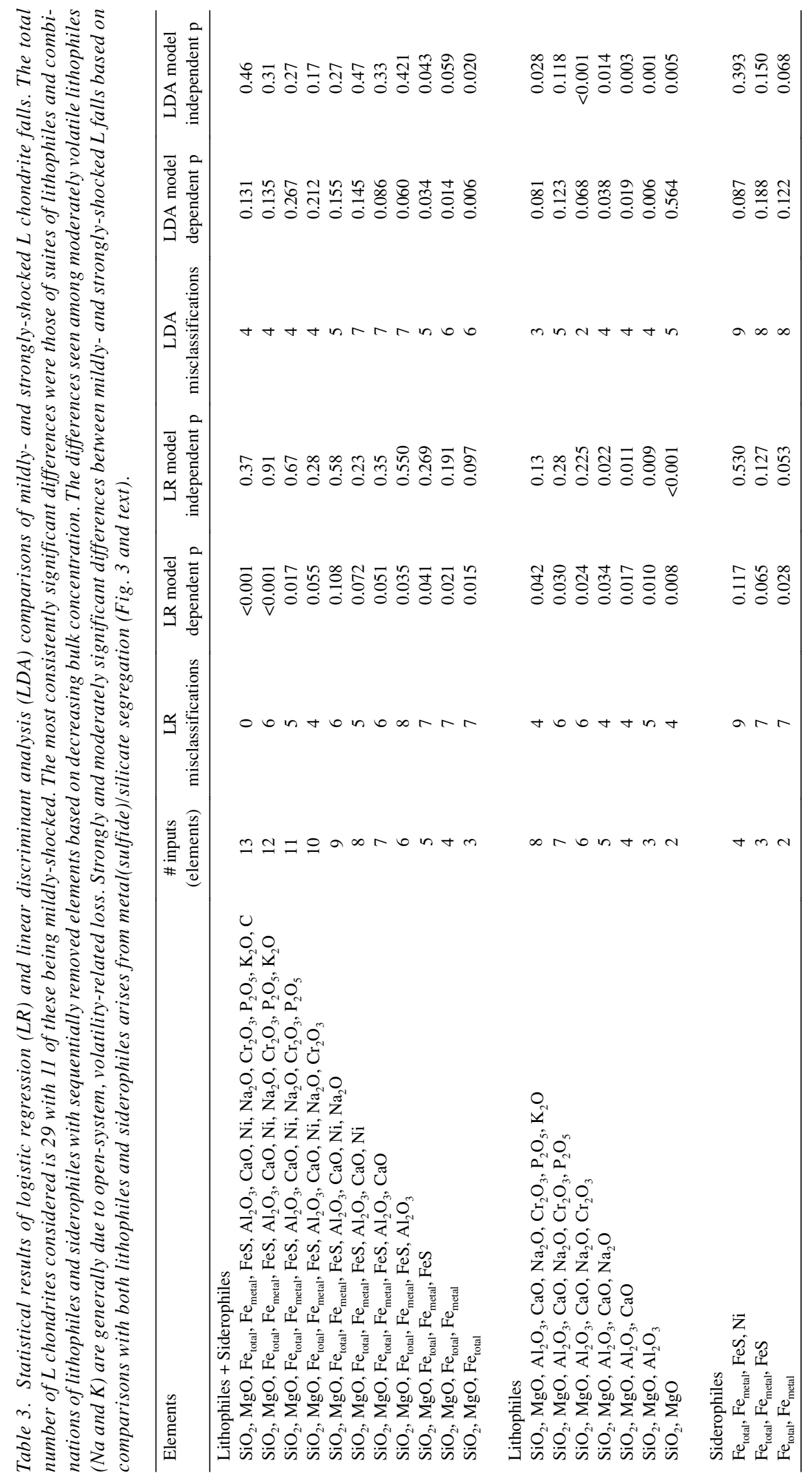




\section{probability of being strongly-shocked}
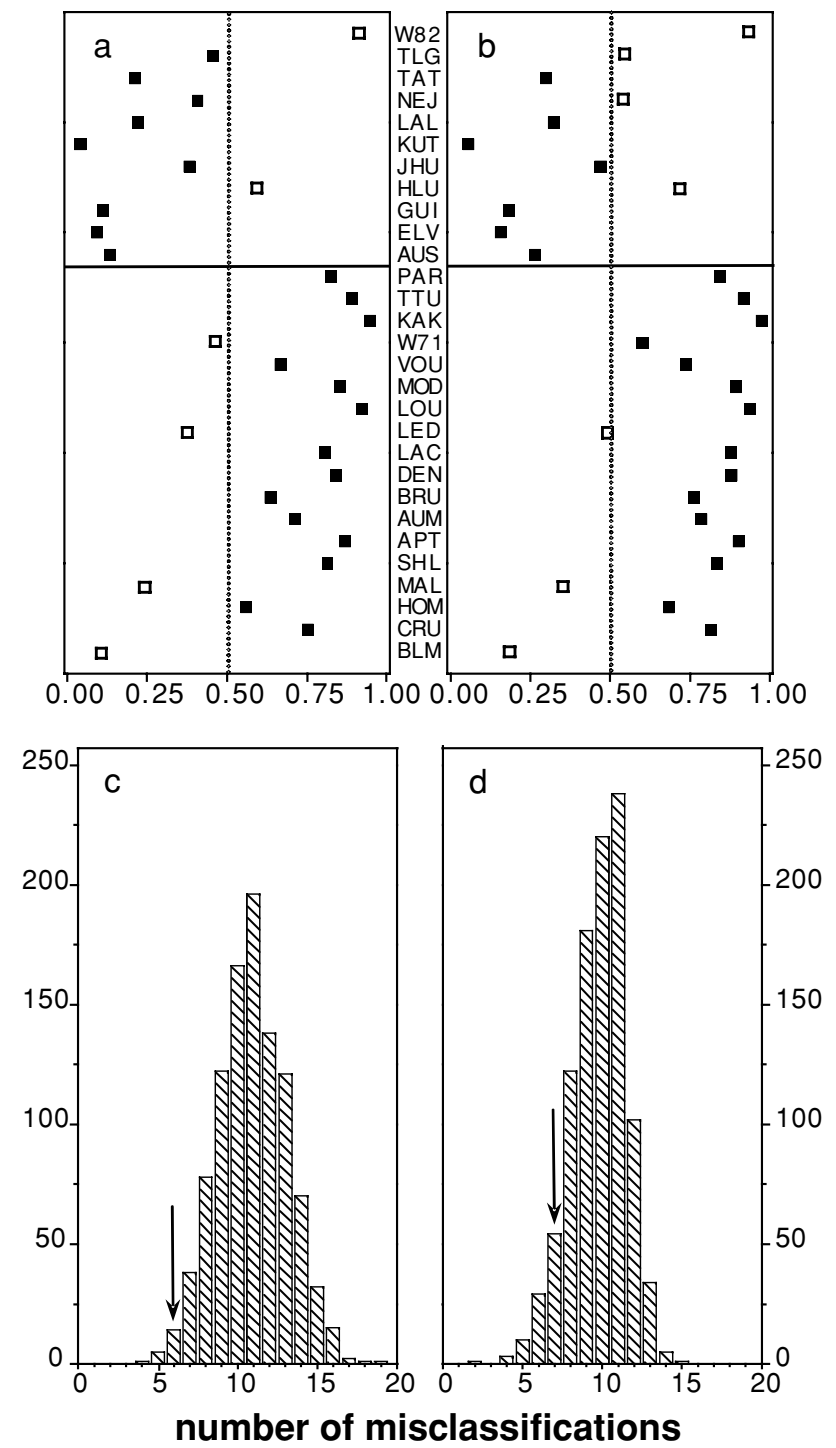

Fig. 5. Moderate to strong evidence for a significant majorelement compositional difference between 11 mildly-and 18 strongly-shocked equilibrated $L$ chondrites based on $\mathrm{SiO}_{2}, \mathrm{MgO}$ and Fe total content. (a) LDA and (b) LR have 6 and 7 misclassifications respectively with model dependent p-values of 0.006 and 0.015. 1000 randomization-simulation trials yielded 20 trials with 6 or fewer misclassifications using the LDA metric (c) and hence, a model-independent p-value of 0.020. The LR case (d) produced 97 runs with 7 or fewer misclassifications and a model-independent p-value of 0.097.

equilibrated $\mathrm{L}$ chondrites based on $\mathrm{SiO}_{2}, \mathrm{MgO}$ and $\mathrm{Fe}_{\text {total }}$ content. Model dependent LDA and LR give 6 and 7 misclassifications respectively with model dependent $\mathrm{p}$ values of 0.006 and 0.015 .1000 randomization-simula- tion trials yielded 20 trials with 6 or fewer misclassifications using the LDA metric and a model-independent $\mathrm{p}$-value of 0.020 . The LR case produced 97 runs with 7 or fewer misclassifications and a model-independent $p$-value of 0.097 . The same procedure was used for other model independent calculations. Model independent LR metric-based comparisons of lithophiles and siderophiles do not show the significance that the model dependent results show. Lithophiles alone compared with model independent LR show highly-significant results for the suite $\left\{\mathrm{SiO}_{2}, \mathrm{MgO}, \mathrm{Al}_{2} \mathrm{O}_{3}, \mathrm{CaO}, \mathrm{Na}_{2} \mathrm{O}\right\}$ and three sequentially "shaved" subsets (Table 3 ). Siderophiles, when examined alone, yield no to moderate significance with respect to shock loading examined with model independent LR. LDA model independent comparisons of lithophiles and siderophiles compare well with the model dependent results showing that the underlying assumptions of this metric may be more valid than those of LR for this suite of elements. Lithophiles, in all cases except one show a strongly significant evidence for a compositional difference. The outlying factor which produces an insignificant result in the LDA lithophile comparisons is $\mathrm{P}_{2} \mathrm{O}_{5}$. Again, this is a result of the great variation in the $\mathrm{P}$ content of the samples, and may be due to the shock-induced formation of phosphate nodules (see below). LDA siderophiles again yield insignificant to a single moderate significant case (the comparison based on $\left.\left\{\mathrm{Fe}_{\text {total }}, \mathrm{Fe}_{\text {metal }}\right\}\right)$. This completes a trend: major element siderophiles, when considered alone, are reluctant to yield a significant statistical result, probably because there is little fractionation among these elements-their suite-internal covariation is not significant because they tend to fractionate together as a group.

In summary, we found moderate to strong evidence for differences between equilibrated $\mathrm{L}$ falls that have experienced mild (S3) and strong (S4-S6) post-metamorphic shock: the most consistently significant differences were those of suites of lithophiles and $\left\{\mathrm{SiO}_{2}, \mathrm{MgO}, \mathrm{Fe}_{\text {total }}\right.$, $\left.\mathrm{Fe}_{\text {metal }}, \mathrm{FeS}\right\}$ with sequentially removed elements based on decreasing bulk concentration. We can now examine the mineralogical effects reflected in the bulk chemistry of these samples and precedents for them.

Differences among refractory lithophile elements such as $\mathrm{Ca}$ and $\mathrm{Al}$ included in my suite demonstrate mineralogical control and in the case the more mobile lithophiles such as $\mathrm{Na}, \mathrm{K}$, and P likely volatility-controlled loss. The apparent differences seen among moderately volatile lithophiles such as $\mathrm{Na}$ and $\mathrm{K}$ are likely due to open-system, volatility-controlled loss (Fig. 3 and Table 3) or possible redistribution within the highly-shocked samples (Xie and Chen, 1996). Loss of Na due to shock-related reheating has specifically been noted in Apt and Vouillé, two of the samples in this suite (Dodd and Jarosewich, 1982a), and redistribution of $\mathrm{Na}$ has been noted in an 
extremely highly-shocked $\mathrm{H}$ chondrite (Xie and Chen, 1996). A similar effect may be expected for K. The reduced $\mathrm{P}$ content in highly-shocked samples may reflect a combination of volatility-controlled loss and, to a greater extent, a drawing out of $\mathrm{P}$ into migrating metal phasesa process which would be enhanced by the partial melting of chondritic metal (Brearley and Jones, 1998). Xie and Chen (1996) noted fine grained phosphate spherules associated with metal and metal sulfides in highlyshocked chondrites and the formation of these nodules or blebs may also explain the high variability of $\mathrm{P}$ within my statistically examined sample suite. At high shock pressures, plagioclase is among the first mineral to transform into melt pocket glass (Dodd and Jarosewich, 1982a; Brearley and Jones, 1998). The slight differences in Ca and $\mathrm{Al}$ content between my mildly- and strongly-shocked suites (Fig. 3 and Table 3) may reflect the slight depletion of such an incipient melt.

Strongly and moderately significant differences between mildly- and strongly-shocked L falls based on comparisons of major lithophiles and siderophiles together arises from metal(sulfide)/silicate segregation. The more extensively shocked samples were heated, probably for extended periods during post-shock episodes, likely up to near the $\mathrm{Fe}(\mathrm{Ni})-\mathrm{Fe}(\mathrm{Ni}) \mathrm{S}$ eutectic of $\sim 960^{\circ} \mathrm{C}$. There is no evidence for complete melting within the statistically considered sample suite, but some evidence for small volumes of silicate melt pockets (Dodd and Jarosewich, 1982a) and discussed below, changes in the opaque phases. The actual physical segregation of metal and silicate likely occurred as intragranular "selective" melts as a result of favorable local contact geometries where the local shock pressures and resulting temperatures were high enough to physically mobilize metal. It has been noted that chondrite samples shocked to stage S4 and higher occasionally contain evidence for once melted (and inherently mobile) metal and troilite (Brearley and Jones, 1998 and references therein) even though bulk rock post shock temperatures were insufficient to produce a whole rock melt (Stöffler et al., 1988). For example, in a study which examined opaque mineral phases in some of the same samples included in this study (e.g., S3 Ausson, S3 Jhung, and S5 Kyushu), Bennett and McSween (1996) observed that troilite melt droplets increase in size and abundance with shock stages at or above S4. In S5 Kyushu, they found evidence for slow cooling from a minimum (whole rock) post shock temperature of $\sim 525^{\circ} \mathrm{C}$ and $\mathrm{FeNi}$ and $\mathrm{Fe}(\mathrm{Ni}) \mathrm{S}$ melt droplets near other opaque grains, whereas in the mildly-shocked Ausson and Jhung, these same melt features were noticeably absent.

Using these observations and the sample sizes from which the chemical analyses were derived, we can place a limit on the scale of post-metamorphic shock-related metal/silicate segregation in L falls. The statistically com- pared samples studied here were prepared from $1.5 \mathrm{~cm}^{3}$ to $4.7 \mathrm{~cm}^{3}$, based on the mean $\mathrm{L}$ chondrite volume density of $3.31 \mathrm{~cm}^{3} / \mathrm{g}$ given by Wilkison et al. (2003), so the physical partitioning of the two constituent phases is discernable in volumes at least this large.

The subtle, but statistically significant, effects we have observed are an example of only an initial stage of metal/ silicate segregation due to shock-related heating. It is clear that the textural characteristics of metal change as maximum shock-induced temperature increases: as shock stage increases, Fe-Ni metal and troilite tend to coalesce first as tiny blebs and veins followed by successively larger metal globules and macro veins (Brearley and Jones, 1998 and Bennett and McSween, 1996). Petrographic precedents of equilibrated $\mathrm{L}$ chondrites which have experienced near complete shock melting or total shock melting are known and complete a consistent sequence while additionally accounting for the observations in this work. The L6 Chico (Norman and Mittlefehldt, 2002), the L chondrite melt rock PAT 91501 (Mittlefehldt and Lindstrom, 2001), L6 Shaw (Taylor et al., 1979) and the L6 Tenham melt breccia (Leroux et al., 2000) are examples of samples where, to different degrees, metal and silicate have been partitioned to an extent much greater than that observed in the samples included in this study because of their reaching higher whole rock temperatures.

Repeated impacts and high residual temperatures in conjunction with shock deformation could account for portions of equilibration and incipient core formation (Rushmer et al., 2005) in planetary differentiation following initial compaction of the original unequilibrated material. The observations made here indicate that without complete melting and only near, but not necessarily at a bulk rock $\mathrm{Fe}(\mathrm{Ni})-\mathrm{Fe}(\mathrm{Ni}) \mathrm{S}$ eutectic temperature, incipient differentiation could have occurred in the early solar system within even small, $\mathrm{cm}$ to $\mathrm{m}$-sized regions of larger objects. It has become clear that condensation, accretion, and differentiation of planet-sized objects occurred relatively quickly within the early solar system (e.g., Halliday et al., 2001). The results shown here suggest that shock-related heating could have played a role in early differentiation of solar system materials.

\section{CONCLUSIONS}

To examine the role of impact related reheating on compositional trends in the major elements of the $\mathrm{L}$ chondrite parent(s), I first examined L falls analyzed by Jarosewich (1990). In an attempt to expand my meteorite-element database beyond that of the Jarosewich (1990) dataset, I compared data produced by others with the multivariate statistical method cluster analysis. When comparing three analysts' analyses of the same three meteorites, I found that there was significant analyst and/ 
or sampling bias (Fig. 1). While all analysts produced highly satisfactory major element data, to eliminate the possibility of bias within statistical comparisons of mildly- and strongly-shocked suite, I used only Jarosewich (1990) data in this study. Among the 37 possible chondrites selected for comparison, 8 of these sample aliquots were analyzed from materials which were prepared from materials that inadequately sampled the metal or silicate phase or were more representatively sampled than the majority of the L falls considered (Fig. 2). These 8 samples were excluded from further consideration because detecting indigenous elemental variations with multivariate analyses can be challenging when additional sources of inconsistently-applied convolved variations are involved.

Suites of mildly-shocked (S3) and strongly-shocked (S4-S6) equilibrated L chondrite falls (Table 1) can be distinguished at statistically significant levels on both model-dependent and -independent bases when compared based on their major element content (Table 3). Graphical comparisons demonstrated that the differences arise because siderophiles are depleted with corresponding mass-balanced lithophile enrichment in strongly-shocked samples (Figs. 3 and 4). The most statistically significant separations involved the most abundant elements (e.g., $\mathrm{Si}, \mathrm{Mg}, \mathrm{Fe}$ ) and lithophiles and while more volatile elements such as $\mathrm{P}$ and $\mathrm{K}$ were recognizably depleted in the strongly-shocked suite of $\mathrm{L}$ falls, the higher variability of these elements makes a statistically significant comparison unfeasible.

The statistical comparisons demonstrated that postmetamorphic shock and associated slow cooling that the strongly-shocked material experienced led to a slight depletion of siderophile content with a mass-balanced gain of bulk lithophile content on the scale of our samples: metal has been removed from these samples to other (nearby) locations within the parent body. Since the samples were derived from volumes between $1.5 \mathrm{~cm}^{3}$ and 4.7 $\mathrm{cm}^{3}$, we can conclude that statistically significant postmetamorphic metal/silicate segregation occurred on a scale at least this large. These results suggest that shockrelated heating could have played a role in the differentiation of solar system materials.

Acknowledgments - I thank E. Jarosewich for sharing the starting masses of Smithsonian Meteorite Powder Collection L chondrite samples, and the Max-Planck-Gesellschaft for support at the Max-Planck-Institut für Chemie in Mainz, Germany, where a portion of this work was completed. Finally, I thank the American Museum of Natural History for support as a Kalbfleisch Research Fellow. Profs. Steven Wolf and Michael Lipschutz supplied helpful discussion. Prof. A. Rubin and an unnamed reviewer helped to improve the manuscript, and comments by Dr. N. Kita were greatly appreciated.

\section{REFERENCES}

Anders, E. (1964) Origin, age, and composition of meteorites. Space Sci. Rev. 3, 583-714.

Bennett, M. E. and McSween, H. Y. (1996) Shock features in iron-nickel metal and troilite of L-group ordinary chondrites. Meteorit. Planet. Sci. 31, 255-264.

Bogard, D. D., Garrison, D. H., Norman, M., Scott, E. R. D. and Keil, K. (1995) ${ }^{39} \mathrm{Ar}-{ }^{40} \mathrm{Ar}$ age and petrology of Chico: Large-scale impact melting on the L chondrite parent body. Geochim. Cosmochim. Acta 59, 1383-1399.

Brearley, A. J. and Jones, R. H. (1998) Chondritic Meteorites. Planetary Materials (Papike, J. J., ed.), 3-1-3-398, Mineralogical Society of America, Washington, D.C., U.S.A.

Chen, M., Sharp, T. G., El Goresy, A., Wopenka, B. and Xie, X. (1996) The majorite-pyrope + magnesiowüstite assemblage: Constraints on the history of shock veins in chondrites. Science 271, 1570-1573.

Dodd, R. T. and Jarosewich, E. (1979) Incipient melting in and shock classification of L-group chondrites. Earth Planet. Sci. Lett. 44, 335-340.

Dodd, R. T. and Jarosewich, E. (1981) Chemical variations among L-group chondrites, III. Major element variation in L6 chondrites. Meteoritics 16, 93-111.

Dodd, R. T. and Jarosewich, E. (1982a) The compositions of incipient melts in L6 chondrites. Earth Planet. Sci. Lett. 59, 355-363.

Dodd, R. T. and Jarosewich, E. (1982b) Petrogenesis of complex veins in the Chantonnay (L6f) chondrite. Earth Planet. Sci. Lett. 59, 364-374.

Everett, B. S. (1993) Cluster Analysis. Wiley \& Sons, Indianapolis, IN, U.S.A., $170 \mathrm{pp}$.

Friedrich, J. M., Bridges, J. C. and Lipschutz, M. E. (2001) Chemical variations with shock loading among equilibrated L chondrite falls. Meteorit. Planet. Sci. 36, A60.

Friedrich, J. M., Bridges, J. C. and Lipschutz, M. E. (2002) Evidence for chemical variation with shock-loading in Lchondrite falls. Lunar Planet. Sci. 33, \#1086.

Friedrich, J. M., Wang, M.-S. and Lipschutz, M. E. (2003) Chemical studies of $\mathrm{L}$ chondrites. V: Compositional patterns for forty-nine trace elements in fourteen L4-6 and seven LL4-6 Falls. Geochim. Cosmochim. Acta 67, 24672479.

Friedrich, J. M., Bridges, J. C., Wang, M.-S. and Lipschutz, M. E. (2004) Chemical studies of L chondrites. VI: Variations with shock-loading among equilibrated $\mathrm{L}$ chondrite falls. Geochim. Cosmochim. Acta 68, 2889-2904.

Grady, M. M. (2000) Catalogue of Meteorites. Cambridge Univ. Press, London, England, 689 pp.

Halliday, A. N., Lee, D.-C., Porcelli, D., Wiechert, U., Schönbächler, M. and Rehkämper, M. (2001) The rates of accretion, core formation and volatile loss in the early Solar System. Phil. Trans. R. Soc. Lond. A 359, 2111-2135.

Heymann, D. (1967) On the origin of hypersthene chondrites: Ages and shock effects of black chondrites. Icarus 6, 189221.

Hörz, F., Cintala, M. J., See, T. H. and Le, L. (2005) Shock melting of ordinary chondrite powders and implications for asteroidal regoliths. Meteorit. Planet. Sci. 40, 1329-1346. 
Huston, T. J. and Lipschutz, M. E. (1984) Chemical studies of L chondrites-III. Mobile trace elements and ${ }^{40} \mathrm{Ar} /{ }^{39} \mathrm{Ar}$ ages. Geochim. Cosmochim. Acta 48, 1319-1329.

Jarosewich, E. (1990) Chemical analyses of meteorites: A compilation of stony and iron meteorite analyses. Meteoritics 25, 323-337.

Kallemeyn, G. W., Rubin, A. E., Wang, D. and Wasson, J. T. (1989) Ordinary chondrites: Bulk compositions, classification, lithophile-element fractionations, and compositionpetrographic type relationships. Geochim. Cosmochim. Acta 53, 2747-2767.

Kimura, M., Chen, M., Yoshida, T., El Goresy, A. and Ohtani, E. (2003) Back-transformation of high-pressure phases in a shock melt vein of an $\mathrm{H}$-chondrite during atmospheric passage: Implications for the survival of high-pressure phases after decomposition. Earth Planet. Sci. Lett. 217, 141-150.

Koblitz, J. (2005) Metbase 7.1 (CDROM).

Kong, P. and Xie, X. (2003) Redistribution of elements in the heavily shocked Yanzhuang chondrite. Meteorit. Planet. Sci. 38, 739-746.

Leroux, H., Doukhan, J.-C. and Guyot, F. (2000) Melt-silicate interaction in quenched shock-induced melt of the Tenham L6-chondrite. Earth Planet. Sci. Lett. 179, 477-487.

Lipschutz, M. E. and Samuels, S. M. (1991) Ordinary chondrites: Multivariate statistical analysis of trace element contents. Geochim. Cosmochim. Acta 55, 19-34.

Mittlefehldt, D. W. and Lindstrom, M. M. (2001) Petrology and geochemistry of Patuxent Range 91501, a clast-poor impact-melt from the L chondrite parent body, and Lewis Cliff 88663, an L7 chondrite. Meteorit. Planet. Sci. 36, 439-457.

Nakamura, N., Fujiwara, T. and Nohda, S. (1990) Young asteroid melting event indicated by $\mathrm{Rb}-\mathrm{Sr}$ dating of the Point of Rocks meteorite. Nature 345, 51-52.

Nittler, L. R., McCoy, T. J., Clark, P. E., Murphy, M. E., Trombka, J. I. and Jarosewich, E. (2004) Bulk element compositions of meteorites: A guide for interpreting remotesensing geochemical measurements of planets and asteroids. Antarctic Meteorite Research 17, 233-253.

Norman, M. D. and Mittlefehldt, D. W. (2002) Impact processing of chondritic planetesimals: Siderophile and volatile element fractionation in the Chico L chondrite. Meteorit. Planet. Sci. 37, 329-344.

Rubin, A. (2004) Postshock annealing and postannealing shock in equilibrated ordinary chondrites: implications for the thermal and shock histories of chondritic asteroids. Geochim. Cosmochim. Acta 68, 673-689.

Rushmer, T., Petford, N., Humayun, M. and Campbell, A. J.
(2005) Fe-liquid segregation in deforming planetesimals: Coupling Core-Forming compositions with transport phenomena. Earth Planet. Sci. Lett. 239, 185-202.

Schmitz, B., Häggström, T. and Tassinari, M. (2003) Sedimentdispersed extraterrestrial chromite traces a major asteroid disruption event. Science 300, 961-964.

Semenenko, V. P. and Golovko, N. V. (1994) Shock-induced black veins and organic compounds in ordinary chondrites. Geochim. Cosmochim. Acta 58, 1525-1535.

Smith, B. A. and Goldstein, J. I. (1977) The metallic microstructures and thermal historiesof severely heated chondrites. Geochim. Cosmochim. Acta 41, 1061-1072.

Stöffler, D. and Langenhorst, F. (1994) Shock metamorphism of quartz in nature and experiment: I. Basic observation and theory. Meteoritics 29, 155-181.

Stöffler, D., Bischoff, A., Buchwald, V. and Rubin, A. G. (1988) Shock effects in meteorites. Meteorites and the Early Solar System (Kerridge, J. F. and Matthews, M. S., eds.), 165202. Univ. Arizona Press, Tucson, AZ, U.S.A.

Stöffler, D., Keil, K. and Scott, E. R. D. (1991) Shock metamorphism of ordinary chondrites. Geochim. Cosmochim. Acta 55, 3845-3867.

Taylor, G. J., Keil, K., Berkley, J. L., Lange, D. E., Fodor, R. V. and Fruland, R. M. (1979) The Shaw meteorite-History of a chondrite consisting of impact-melted and metamorphic lithologies. Geochim. Cosmochim. Acta 43, 323-337.

Tomioka, N. and Fujino, K. (1997) Natural (Mg, Fe)SiO $3^{-}$ ilmenite and -perovskite in the Tenham meteorite. Science 277, 1084-1086.

Walsh, T. M. and Lipschutz, M. E. (1982) Chemical studies of L chondrites-II. Shock-induced trace element mobilization. Geochim. Cosmochim. Acta 46, 2491-2500.

Wilkison, S. L., McCoy, T. J., McCamant, J. E., Robinson, M. S. and Britt, D. T. (2003) Porosity and density of ordinary chondrites: Clues to the formation of friable and porous ordinary chondrites. Meteorit. Planet. Sci. 38, 1533-1546.

Wilson, A. D. (1964) The sampling of silicate rock powder for chemical analysis. Analyst 89, 18-30.

Wolf, S. F. and Lipschutz, M. E. (1995a) Chemical studies of H chondrites-4. New data and comparison of Antarctic populations. J. Geophys. Res. 100, 3297-3316.

Wolf, S. F. and Lipschutz, M. E. (1995b) Multivariate statistical techniques for trace element analysis. Adv. Anal. Geochem. 2, 241-281.

Xie, X. and Chen, M. (1996) Na-redistribution in the melt phase of Yanzhuang meteorite. Ant. Met. XXI, 200-203. 